\title{
The rectal mucosa-associated microflora in patients with ulcerative colitis
}

\author{
M. GILLIAN HARTLEY, M. J. HUDSON,* E. T. SWARBRICK,† M. J. HILL, A. E. GENT,‡ \\ M. D. HELLIER§ and R. H. GRACE\|
}

Pathology Division, PHLS Centre for Applied Microbiology and Research, Porton Down, Salisbury, SP4 OJG, †New Cross Hospital, Wolverhampton, WV10 OOP, $¥$ The General Infirmary, Salisbury, SP2 7SX, §Princess Margaret Hospital, Swindon, SN1 4JU and \|The Royal Hospital, Wolverhampton, WV2 1BT

\begin{abstract}
Summary. The rectal mucosa-associated flora (MAF) of patients with ulcerative colitis has been studied in 25 patients with newly diagnosed disease, 20 with relapse of existing disease, and 44 who were in remission. Patients with active disease were re-examined twice during treatment. The MAF was simpler and less dense than the microflora of faeces. Obligate anaerobes usually predominated in the MAF although the ratio of obligate anaerobes to facultative species was lower than that found in faeces. Viable counts of the total flora and of its constituent genera varied considerably between patients. Counts of the total flora, of obligate anaerobes (including bifidobacteria, eubacteria and clostridia), and facultative organisms and micro-aerobes (enterobacteria and lactobacilli) were reduced in patients with active disease compared with those with inactive disease; corresponding carriage rates were also lower. Counts and carriage rates increased during treatment and approached those found in quiescent disease. The alterations in the MAF were especially marked in patients experiencing their first attack of ulcerative colitis. The relationship between these alterations and the aetiology and pathogenesis of this disease remains unclear.
\end{abstract}

\section{Introduction}

The aetiology of ulcerative colitis (UC) is unknown, ${ }^{1}$ but the characteristic and unexplained chronic inflammatory response strongly suggests that the pathological basis of this disease is chronically altered intestinal immune response. ${ }^{2}$ This alteration includes chronic immunocyte infiltration and activation, local immune complex deposition, complement activation and autoimmune phenomena. ${ }^{3,4}$ The nature and sources of the provoking antigen or antigens involved in these processes are not known and may differ between individual patients. In the acute stages, UC shares many pathological features with infectious colitis but thereafter follows a characteristic chronic and relapsing course with chronic inflammatory lesions and epithelial destruction in the absence of infection by enteric pathogens. ${ }^{5}$ Chronically damaged intestinal mucosa would be expected to be more permeable to provoking antigens or metabolites, thus perpetuating the lesion.

The intestinal lesions of UC are confined to the mucosa of the colon and rectum and occur only in an intact and functional large bowel. ${ }^{5}$ Therefore, it is likely that the intestinal microflora plays an important

Received 19 Dec. 1990; revised version accepted 30 April 1991. * Correspondence should be sent to Mr M. J. Hudson. rôle in the pathogenesis of UC. The mechanisms for such an involvement are not known but could include mucosal invasion, by acting directly as provoking microbial antigens, by the production of antigens from the metabolism of endogenous or dietary substrates, or by the elaboration of toxins and metabolites toxic to the cells of the colorectal epithelium. The majority of investigations into the rôle played by intestinal microbes in UC have studied the faecal flora. Despite numerous investigations over the last half century, no aetiological agent has been identified nor have any consistent alterations in the balance or composition of this flora been found. ${ }^{5,6}$

The mucosa of the colon and rectum of man harbours a distinct microflora that is closely associated with the mucosal surfaces and crypts and lies beneath the mucus blanket. This mucosa-associated flora (MAF) has been characterised in individuals with no significant bowel disease $e^{7,8}$ and in patients with idiopathic inflammatory bowel disease ${ }^{9-11}$ and neoplasia. ${ }^{9}$ The MAF occupies an unique anatomical position from whence to exert direct and local damage to the mucosa or, alternatively, to protect these tissues against invasion or damage by luminal microbes or their metabolites. This flora is likely to play an important rôle in the modulation of colonisation resistance in the large intestine. Analysis of the MAF should therefore yield important clues to the rôle of microbes in the aetiology and pathogenesis of UC. 
This paper reports the characterisation of the rectal MAF of patients at first presentation with active UC. Previous studies have shown that there is considerable variation in the rectal MAF between individual patients. ${ }^{11}$ To minimise this problem, we monitored the MAF of each patient twice during the treatment of their colitis; the results were compared with those from patients with relapse of UC and also patients with colitis in remission.

\section{Materials and methods}

\section{Patients and samples}

Samples were obtained from patients presenting for diagnosis or treatment at four District General Hospitals participating in a collaborative research programme into various aspects of diagnosis and management of idiopathic inflammatory bowel disease (The Inflammatory Bowel Disease Study Group). The protocols for the present study were approved by local Ethics Committees and informed consent was obtained from each patient.

Ulcerative colitis was diagnosed by conventional clinical criteria and investigations included routine sigmoidoscopy and rectal biopsy. Diagnosis was confirmed by typical histology of involved tissues and supported by findings from radiological and endoscopic examinations when these were indicated.

Rectal biopsy tissue samples were taken at routine sigmoidoscopy. No bowel preparation was used. Lubricant gel (K-Y Lubricating Jelly, Johnson and Johnson Ltd) was applied sparingly to the sigmoidoscope when necessary. Biopsy samples were taken from the rectosigmoid junction of 25 patients at first presentation with untreated, active UC. Samples of rectal faeces and venous blood were also taken for related studies. Further biopsy samples were obtained from each patient after treatment for 3 and 12 weeks with sulphasalazine and steroids as appropriate. A comparable set of samples was taken from 20 patients with relapse of previously diagnosed and treated ulcerative colitis. Where possible, a complete set of three biopsy samples, or at least two, was obtained from each of these patients. For comparison, single biopsy samples were taken at routine follow-up examination of 44 patients with quiescent UC; ethical considerations precluded taking a comparable series of samples from these patients. Disease severity at the time each sample was taken was determined from patient records of relevant clinical symptoms. Patients were classified as quiescent colitics if they had been free of overt clinical disease for at least 6 months.

\section{Sample storage}

Rectal biopsy samples were placed, unwashed, in peptone broth containing glycerol as a cryoprotectant and immediately snap frozen in liquid nitrogen or on dry ice for subsequent storage at below $-35^{\circ} \mathrm{C}^{1{ }^{1,12}}$ Serum and faeces were stored frozen without treatment.

\section{Microbiological techniques}

Biopsy samples were thawed rapidly within the oxygen-free atmosphere of a flexible-film anaerobic chamber and processed by established procedures. ${ }^{11,13,14}$ Media and solutions were steamed, or heated in a microwave oven to free them from dissolved oxygen immediately before transfer into the anaerobic chamber for immediate use or storage overnight. Heat-sensitive sterile solutions were prepared within the chamber by membrane filtration. All plastic ware (petri dishes, 7-ml sample bottles, micropipette tips, inoculating loops, stomacher bags, etc.) was stored in the chamber for at least $18 \mathrm{~h}$ (overnight) to remove adsorbed oxygen.

Each biopsy sample was washed thoroughly by vortex mixing in three changes of $c .5 \mathrm{ml}$ of anaerobic diluent to remove loosely adherent faecal material and mucus. The diluent was made isotonic to minimise absorption of water by the tissue and contained peptone to maximise recovery of gut bacteria. ${ }^{15,16}$ The composition of the diluent was proteose-peptone (Oxoid) $1 \%$ in Ringer solution with cysteine $\mathrm{HCl} 0.5 \mathrm{~g} /$ $\mathrm{L}$, dithiothreitol $0.3 \mathrm{~g} / \mathrm{L}$ and resazurin $2 \mathrm{mg} / \mathrm{L}$. The weighed biopsy sample was macerated in a known volume of diluent in a Colworth Stomacher. Triplicate $25-\mu \mathrm{l}$ samples of a decimal dilution series prepared in brain-heart infusion broth were used to inoculate lightly dried agar media by a modification of the technique of Miles, Misra and Irwin ${ }^{17}$ as described previously. ${ }^{11}$ A range of non-selective, selective and differential media were inoculated (table I). ${ }^{18,19,20}$ Portions of the dilution series were also treated with Tyndallised absolute ethanol $(50 \% \mathrm{v} / \mathrm{v}$ final concentration) for $1 \mathrm{~h}$ at room temperature to select sporeforming clostridia and bacilli ${ }^{11,21}$ and triplicate $50-\mu \mathrm{l}$ samples were used to inoculate egg-yolk agar.

Extremely oxygen-sensitive obligate anaerobes were sought and subcultured on M10-AC, a habitatsimulating medium prepared and incubated only within the anaerobic chamber. M10-AC was the prereduced and anaerobically sterilised (PRAS) medium 10 of Caldwell and Bryant ${ }^{22}$ including modifications suggested by Mitsuoka ${ }^{23}$ and others. ${ }^{15,24}$ It was further modified by including proteose peptone, pectin and partially-purified hog-gastric mucin as complex nutrients and 3-phenylpropionic acid (hydrocinnamic acid $)^{25}$ in the volatile fatty acid supplement. The complete medium was re-formulated as two doublestrength stock solutions for ease of preparation, storage and use within an anaerobic chamber. The doublestrength broth base contained the following $(/ \mathbf{L})$ : glucose, cellobiose, soluble potato starch, pectin (Sigma), and purified hog gastric mucin (type III, Sigma), $1 \mathrm{~g}$ of each; tryptone (Oxoid L42) and proteose-peptone (Oxoid L85), 2 g of each; neutralised 
Table I. Bacteriological media

Media incubated anaerobically

M10-AC; non-selective, pre-reduced, habitat-simulating (see Materials and methods).

Modified Brain-Heart Infusion (BHI) blood agar; non-selective; contains volatile fatty acids to improve habitat-simulating properties. ${ }^{18}$

BHI-kanamycin-vancomycin; selective for Bacteroides spp. ${ }^{19}$

BHI-rifampicin; selective for Eubacterium spp. and C. ramosum.

Bifidobacterium Agar $:{ }^{14}$ with maltose, fructose and lactose. BHI-cefoxitin-cycloserine (Oxoid); selective for $C$. difficile. Willis and Hobbs egg-yolk medium for clostridia.

Fastidious Anaerobe Agar (Lab M Ltd) with spectinomycin and polymyxin; selective for intestinal anaerobic spirochaetes. ${ }^{20}$

Media incubated micro-aerobically

Columbia blood bi-layer agar (Oxoid); non-selective.

Mitis-Salivarius Agar (Difco) for oral streptococci.

Rogosa's SL medium (Oxoid) for lactobacilli.

Skirrow's Campylobacter blood agar (Oxoid).

Media incubated aerobically

Columbia blood bi-layer agar (Oxoid); non-selective.

MacConkey's agar (Oxoid) for enterobacteria and enterococci.

Gentamicin-thallous acetate-carbonate agar for Group D streptococci.

CIN agar (Oxoid); selective for Yersinia spp.

Media from reference ${ }^{11}$ except where indicated.

liver digest (Oxoid L27) and yeast extract (Oxoid L21), $1 \mathrm{~g}$ of each; ascorbic acid $1 \mathrm{~g}$; antifoam (Toray Silicone SH5535) $1 \mathrm{ml}$; haemin solution $(0.5 \mathrm{~g} / \mathrm{L}$ in $0.1 \mathrm{M}$ $\mathrm{NaOH}) 20 \mathrm{ml}$; vitamin $\mathrm{K}_{1}(1 \mathrm{~g} / \mathrm{L}$ in ethanol) $2 \mathrm{ml}$; cresyl violet acetate $(2 \mathrm{~g} / \mathrm{L}) 1 \mathrm{ml}$; M10 Mineral Solutions I and II, $75 \mathrm{ml}$ of each; trace minerals and trace vitamin solutions, ${ }^{26} 20 \mathrm{ml}$ of each; M10 volatile fatty acid supplement $6.2 \mathrm{ml}$ and 3-phenylpropionic acid $2 \mathrm{mg}$. The double-strength agar was purified agar (Oxoid L28) 3\% prepared in ACES-KOH (5 mM final concentration, $\mathrm{pH} \mathrm{7.0)}$ with resazurin $2 \mathrm{mg} / \mathrm{L}$. The autoclaved, double-strength stock solutions were stored within the anaerobic chamber. For use, equal volumes of the broth and melted agar $\left(50^{\circ} \mathrm{C}\right)$ were combined, cysteine $\mathrm{HCl} 0.5 \mathrm{~g} / \mathrm{L}$, dithiothreitol $0.3 \mathrm{~g} / \mathrm{L}$ and sodium bicarbonate $2 \mathrm{~g} / \mathrm{L}$ were added as filtersterilised $(0.2 \mu \mathrm{m})$ solutions, and the complete medium was poured as plates. The concentration of bicarbonate in the complete medium was selected to give a final $\mathrm{pH}$ of $7.2 \pm 0.2$ after equilibration in the anaerobic chamber atmosphere of $\mathrm{CO}_{2} c .10 \%$.

Inoculated media, except M10-AC and Clostridium difficile-selective agar, were removed from the anaerobic chamber for incubation. Anaerobic plates were removed inside anaerobic jars containing active palladium catalyst. Inoculated media were incubated under the appropriate atmospheres at $37^{\circ} \mathrm{C}$. Yersinia spp. were sought on selective medium incubated at $30^{\circ} \mathrm{C}$. Plates incubated in air or in a micro-aerobic incubator $\left(\mathrm{CO}_{2} 10 \%, \mathrm{O}_{2} 5 \%\right.$ in $\left.\mathrm{N}_{2},>90 \% \mathrm{RH}\right)$ were examined after 2 days, plates incubated anaerobically $\left(\mathrm{CO}_{2} 10 \%\right.$ in $\left.\mathrm{H}_{2},>90 \% \mathrm{RH}\right)$ after 5-7 days. M10-AC plates were incubated within the anaerobic chamber atmosphere $\left(\mathrm{CO}_{2} 10 \%, \mathrm{H}_{2} 10 \%\right.$ in $\left.\mathrm{N}_{2},>90 \% \mathrm{RH}\right)$ for
5-8 days. Intestinal spirochaetes were sought microscopically in the macerate and by anaerobic culture on plates of selective medium which were examined weekly for 3 weeks.

Bacterial colonies growing on each medium were counted and, where possible, differentiated at least to genus level. Some less easily differentiated isolates, including the anaerobic gram-positive cocci and the non-bifidobacterial, non-eubacterial, anaerobic grampositive rods, were grouped phenotypically only. If similar isolates were recovered on both selective and non-selective media, the count from the latter was used in calculations. Aerobes, facultative organisms and micro-aerophiles were identified by conventional methods. Obligate anaerobes were identified by absence of, or very poor, aerobic or micro-aerobic growth, morphology in gram-stained smears, fatty acid end-product analysis by gas-liquid chromatography ${ }^{14}$ and various selected biochemical tests. ${ }^{24}$ Representative isolates from each sample were stored frozen at $-35^{\circ} \mathrm{C}$ in nutrient broth containing dimethylsulphoxide (DMSO) $10 \%$ as cryoprotectant for subsequent studies.

\section{Statistical analyses}

Bacterial counts are expressed as $\log _{10} \mathrm{cfu} / \mathrm{g}$ biopsy tissue (wet weight) ${ }^{27}$ and the data were analysed by appropriate statistical methods - analysis of variance (ANOVA), Student's $t$ test, $\chi^{2}$-test, and linear regression. Differences of $p<0.05$ were deemed to be significant. Two-sided tests were used unless otherwise indicated. Multiple linear regression was used to determine the effect on bacterial counts of clinical variables such as extent of disease, severity and treatment regimens. For each patient, the response variable (whether bacterial count or clinical variable) was assumed to be independent at each of the three time points.

To be able to include those samples that apparently lacked a particular bacterial group (i.e., none detected), we substituted into our calculations an arbitrary value of one half of the lower limit of detection, calculated for that sample.

\section{Results}

All but two rectal mucosal biopsy samples yielded a cultivable microflora; the range of logarithmic counts was from $8.6 / \mathrm{g}$ of tissue $\left(4.0 \times 10^{8} / \mathrm{g}\right)$ to below the limit of detection $\left(c .3 .0 / \mathrm{g}, 1 \times 10^{3} / \mathrm{g}\right)$ and the median count was $6 \cdot 1 \mathrm{~g}\left(1 \cdot 3 \times 10^{6} / \mathrm{g}\right)$. Regression analysis on the total flora and major genera present indicated that there was no significant loss of bacterial viability as a result of frozen storage for up to 36 months $(p=0 \cdot 3)$. Similarly, there was no evidence for any selective loss of individual genera during storage.

Bacterial genera present in the MAF were similar to those found in the normal faecal flora but differed 
in several respects, notably in a lower ratio of obligate anaerobes to facultative organisms, reduced numbers of bacteria, reduced complexity and an altered balance of genera (data not shown). Obligate aerobes (bacilli and micrococci), yeasts and fungi were isolated only rarely.

Although specific enrichment procedures were not used, enteric bacterial pathogens were not isolated, with the exception of $C$. difficile; this was isolated from three patients (two with "new" and one with relapsed UC) during active treatment with sulphasalazine. Intestinal spirochaetes and campylobacters were neither observed nor cultured from any sample.

Table II summarises the rectal MAF of 25 patients with newly diagnosed, active UC before specific treatment was given. The flora was composed predominantly of obligate anaerobes, particularly anaerobic gram-positive cocci and bacteroides. The transformed data shows good correspondence of means and median values for the counts. The wide variation in counts of the flora between individual patients is evident from the estimates for the spread of the data. This variability was seen in each of the patient groups and limited the sensitivity of statistical comparisons between groups.

Table III shows the microbiological data for the same 25 "new" UC patients before and twice during treatment. The median values and ranges are omitted from this table for simplicity. Treatment with sulphasalazine or topical steroids, or both, was very effective and all patients improved clinically. The complexity of the flora of each patient appeared to increase after treatment, as judged by an increase in the variety of colony types present. The total flora, counts and carriage rates of the majority of the genera increased during this treatment period, although only achieving statistical significance for the unidentified facultative and anaerobic gram-positive rods. The increase in total count, and counts of total obligate anaerobes, bacteroides, eubacteria and streptococci just failed to reach statistical significance $(0 \cdot 1>p>0 \cdot 05)$. Multivariate analysis showed that these alterations were unrelated to the treatment used $(p>0 \cdot 5)$. Counts and carriage rates of the MAF after 3 weeks were generally intermediate between the 0 and 12-week values.

Table IV summarises the rectal MAF from 44 patients with quiescent disease. The flora was composed predominantly of obligate anaerobes, particularly bifidobacteria, bacteroides and anaerobic grampositive cocci. There were neither marked nor significant differences between the flora of these patients and that of the "new" patients studied at 12 weeks. However, counts or carriage rates, or both, of bifidobacteria, eubacteria, clostridia, propionibacteria, lactobacilli and enterobacteria were significantly higher than the values for untreated, active disease (table II) and, as such, follow the trend observed in these patients during treatment. In contrast, anaerobic gram-positive cocci, bacteroides, streptococci and staphylococci were isolated less frequently.

There was no indication that the composition of the flora was influenced by either the severity of the most recent attack, the anatomical extent of previous

Table II. Rectal MAF of 25 patients with untreated active UC

\begin{tabular}{|c|c|c|c|c|c|}
\hline \multirow{2}{*}{ MAF } & \multirow{2}{*}{$\begin{array}{l}\text { Carriage } \\
\text { rate }(\%)\end{array}$} & \multicolumn{4}{|c|}{ Bacterial count ( $\log _{10} \mathrm{cfu} / \mathrm{g}$ wet weight) } \\
\hline & & Mean & SD & Median & Range* \\
\hline Total flora & 100 & $5 \cdot 41$ & 0.89 & $5 \cdot 32$ & $3 \cdot 69-7 \cdot 48$ \\
\hline $\begin{array}{l}\text { Obligate anaerobes } \\
\text { Gram-positive }\end{array}$ & 96 & $5 \cdot 19$ & $1 \cdot 03$ & $5 \cdot 23$ & ND- $7 \cdot 45$ \\
\hline Actinomyces & 4 & - & - & - & ND $-4 \cdot 38$ \\
\hline Anaerobic cocci & 88 & $4 \cdot 76$ & $1 \cdot 08$ & $4 \cdot 59$ & ND $-7 \cdot 20$ \\
\hline Bifidobacteria & 60 & $4 \cdot 03$ & $1 \cdot 06$ & $3 \cdot 89$ & ND-6.90 \\
\hline Clostridia & 44 & $3 \cdot 37$ & $0 \cdot 51$ & $3 \cdot 29$ & ND $-4 \cdot 79$ \\
\hline Eubacteria & 43 & $3 \cdot 81$ & $1 \cdot 04$ & $3 \cdot 39$ & ND -6.51 \\
\hline Propionibacteria & 4 & - & - & - & ND-4.46 \\
\hline Other rods & 52 & $3 \cdot 65$ & $0 \cdot 78$ & $3 \cdot 39$ & ND $-5 \cdot 12$ \\
\hline \multicolumn{6}{|l|}{ Gram-negative } \\
\hline Bacteroides & 92 & $4 \cdot 51$ & 0.90 & $4 \cdot 53$ & ND $-6 \cdot 20$ \\
\hline Fusobacteria & 4 & - & - & - & ND- $5 \cdot 60$ \\
\hline Veillonella & 4 & - & - & - & ND-3.48 \\
\hline Facultative aerobic organisms & 100 & 4.49 & 0.94 & $4 \cdot 51$ & $3 \cdot 20-6 \cdot 00$ \\
\hline \multicolumn{6}{|l|}{ Gram-positive } \\
\hline Bacilli & 8 & - & - & - & ND -3.56 \\
\hline Lactobacilli & 24 & 3.45 & $0 \cdot 84$ & $3 \cdot 18$ & ND-5.36 \\
\hline Other rods & 20 & $3 \cdot 29$ & 0.63 & $3 \cdot 18$ & ND $-5 \cdot 56$ \\
\hline Streptococci & 88 & $3 \cdot 91$ & 0.68 & $3 \cdot 66$ & ND-5.38 \\
\hline Staphylococci & 60 & $3 \cdot 57$ & $0 \cdot 76$ & $3 \cdot 30$ & ND -4.95 \\
\hline \multicolumn{6}{|l|}{ Gram-negative } \\
\hline Enterobacteria & 36 & $3 \cdot 50$ & $0 \cdot 84$ & $3 \cdot 22$ & ND-5.63 \\
\hline Anaerobe : aerobe ratio & & \multicolumn{4}{|c|}{ mean $16: 1($ median $6: 1)$} \\
\hline
\end{tabular}

ND, not detected; - , not calculated.

* Where carriage rate was $<20 \%$, only the range is given; ratios are rounded to the nearest integer. 
Table III. The rectal MAF of patients with newly diagnosed UC before and during treatment

\begin{tabular}{|c|c|c|c|c|c|c|}
\hline \multirow[b]{3}{*}{ Total flora } & \multicolumn{6}{|c|}{ Mean bacterial count $\left(\log _{10} \mathrm{cfu} / \mathrm{g}\right)(\mathrm{SD})$ and percentage carriage rate* } \\
\hline & \multicolumn{2}{|r|}{ untreated } & \multicolumn{2}{|c|}{3 weeks treatment } & \multicolumn{2}{|c|}{12 weeks treatment } \\
\hline & $5 \cdot 41$ & $(0 \cdot 89) \quad 100 \%$ & $5.64 \quad(0.99)$ & $100 \%$ & $5.96 \quad(1.05) \quad 1$ & $100 \%$ \\
\hline Obligate anaerobes & $5 \cdot 19$ & $(1.03) \quad 96 \%$ & $5.48 \quad(0.98)$ & $100 \%$ & $5 \cdot 79 \quad(1 \cdot 20)$ & $96 \%$ \\
\hline \multicolumn{7}{|l|}{ Gram-positive } \\
\hline Actinomyces & ND 4 & $4 \cdot 38$ & ND-5.38 & $8 \%$ & ND & \\
\hline Anaerobic cocci & $4 \cdot 76$ & $(1.08) \quad 88 \%$ & $4 \cdot 68 \quad(1 \cdot 03)$ & $84 \%$ & $5.03 \quad(1 \cdot 10)$ & $88 \%$ \\
\hline Bifidobacteria & $4 \cdot 03$ & $(1.06) \quad 60 \%$ & $4 \cdot 15 \quad(1 \cdot 02)$ & $64 \%$ & $4 \cdot 36 \quad(1 \cdot 27)$ & $71 \%$ \\
\hline Clostridia & $3 \cdot 37$ & $(0.51) \quad 44 \%$ & $3.65 \quad(0.88)$ & $44 \%$ & $3.70 \quad(0.78)$ & $38 \%$ \\
\hline Eubacteria & $3 \cdot 81$ & $(1.04) \quad 43 \%$ & $3.39 \quad(0.83)$ & $48 \%$ & $4 \cdot 24 \quad(1 \cdot 21)$ & $67 \%$ \\
\hline Propionibacteria & ND -4 & $4.46 \quad 4 \%$ & ND $-4 \cdot 42$ & $12 \%$ & ND $-6 \cdot 92$ & $17 \%$ \\
\hline Other rods & $3 \cdot 65$ & $(0.78) \quad 52 \%$ & $3.94 \quad(1.03)$ & $44 \%$ & $4.77 \quad(1.45) \dagger$ & $79 \%+$ \\
\hline \multicolumn{7}{|l|}{ Gram-negative } \\
\hline Bacteroides & $4 \cdot 51$ & $(0.90) \quad 92 \%$ & $4.75 \quad(1.09)$ & $84 \%$ & $5 \cdot 08 \quad(1 \cdot 10)$ & $96 \%$ \\
\hline Fusobacteria & ND- 5 & $5 \cdot 60$ & ND-5 20 & $8 \%$ & ND-6.15 & $4 \%$ \\
\hline Veillonella & ND-3 & $4 \%$ & ND-5.34 & $16 \%$ & ND-4.99 & $9 \%$ \\
\hline Facultatives/Aerobes & $4 \cdot 49$ & $(0.94) 100 \%$ & $4.79 \quad(0.93)$ & $100 \%$ & $4.96 \quad(0.94)$ & $96 \%$ \\
\hline \multicolumn{7}{|l|}{ Gram-positive } \\
\hline Bacilli & ND-3 & $8 \%$ & ND-3.88 & $12 \%$ & ND $-3 \cdot 32$ & $9 \%$ \\
\hline Lactobacilli & 3.45 & $(0.84) \quad 24 \%$ & $3.74 \quad(0.91)$ & $48 \%$ & $3.74 \quad(0.95)$ & $38 \%$ \\
\hline Other rods & $3 \cdot 29$ & $(0.63) \quad 20 \%$ & $3.66 \quad(1.03)$ & $32 \%$ & $3.85 \quad(0.96)$ & $46 \%$ \\
\hline Streptococci & 3.91 & $(0.68) \quad 88 \%$ & $4 \cdot 18 \quad(0 \cdot 94)$ & $88 \%$ & $4 \cdot 41 \quad(1 \cdot 14)$ & $75 \%$ \\
\hline Staphylococci & 3.57 & $(0 \cdot 76) \quad 60 \%$ & $3.48 \quad(0.59)$ & $40 \%$ & $3.55 \quad(0.57)$ & $50 \%$ \\
\hline \multicolumn{7}{|l|}{ Gram-negative } \\
\hline Enterobacteria & $3 \cdot 50$ & $(0 \cdot 84) \quad 36 \%$ & $3 \cdot 65 \quad(0 \cdot 79)$ & $40 \%$ & $3.75 \quad(0 \cdot 86)$ & $46 \%$ \\
\hline Anaerobe; aerobe ratio $\S$ & $16: 1$ & $(6: 1)$ & $20: 1 \quad(8: 1)$ & & $244: 1 \quad(7: 1)$ & \\
\hline
\end{tabular}

ND, not detected.

* Where carriage rate was $<20 \%$, only the range is given.

+ Significantly different ( $\mathrm{p}<0 \cdot 001)$ from patients with "new" untreated UC.

$¥$ Significantly different $(\mathrm{p}<0.05)$ from patients with "new" untreated UC.

$\S$ Mean (median) ratio rounded to integer.

Table IV. Rectal MAF of 44 patients with equivalent UC

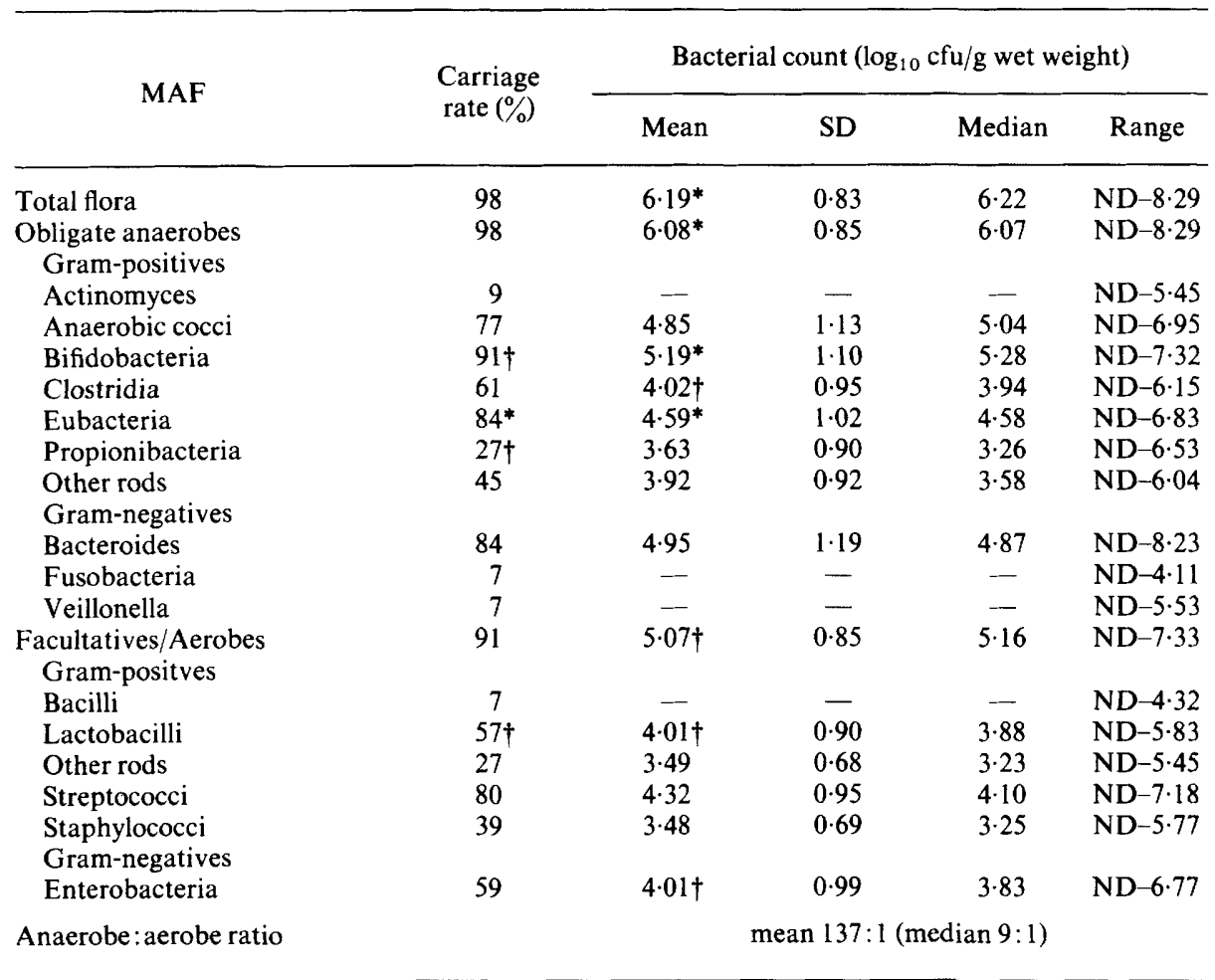

ND, not detected.

* Significantly greater $(\mathrm{p}<0.001)$ than patients with "new" untreated UC.

† Significantly greater $(\mathrm{p}<0.05)$ than patients with "new" untreated UC. 
Table $\mathbf{V}$. The rectal MAF of patients with relapsed UC, studied before and during treatment

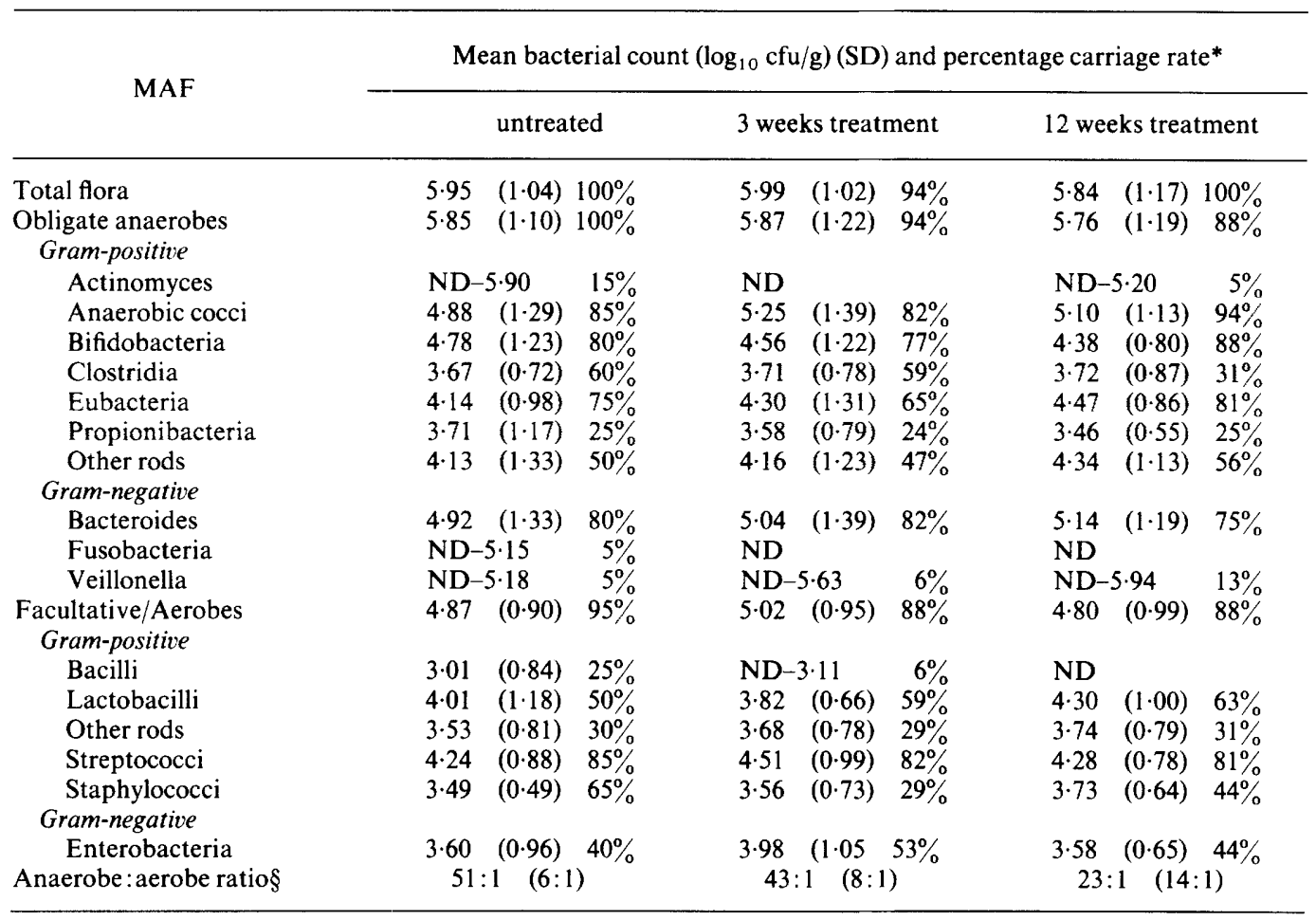

See footnote to table III.

disease or the time in remission (up to 13 years). Sulphasalazine was the long term treatment used by $21(48 \%)$ of the 44 patients with quiescent disease and this appeared to have no selective effect on the MAF.

Table V shows the bacterial counts for the comparative group of 16 patients with relapse of existing colitis examined before and twice during treatment. The trend in alterations to the MAF in these relapse patients, although less pronounced and not achieving statistical significance, was similar to that observed in the equivalent samples from the patients with newly diagnosed UC. Counts of both obligate anaerobes and facultative organisms were reduced, particularly the bifidobacteria, clostridia, eubacteria and enterobacteria. Anaerobic gram-positive cocci, streptococci and staphylococci were isolated more frequently.

Considered as a group, the relapse patients appeared to have more severe disease than was seen in the newly diagnosed patients. Treatment with sulphasalazine or steroids, or both, was again successful in achieving symptomatic improvement and remission of colitis. Although eight $(50 \%)$ of the 16 patients presenting with relapsed UC were taking sulphasalazine as a maintenance treatment at the time of their relapse, their colitis was no less severe and this treatment did not appear to affect the nature of the MAF.

The composition of the MAF for different patient groups was also determined with respect to the predominant genus or phenotypic group found in each sample, and thus was independent of the density of the flora. Anaerobic gram-positive cocci and bacteroides were the predominant organisms in active disease, whether newly diagnosed or relapsed UC, whereas bifidobacteria predominated in quiescent disease (table VI). Genera other than those indicated, including eubacteria, clostridia, lactobacilli and unidentified anaerobic gram-positive rods ("other genera") were predominant in relatively few samples; there was no obvious relationship between any component of this group and disease activity.

We found no obvious relationship between altered bowel function (stool consistency, bowel frequency and presence of frank blood in stool) and either qualitative or quantitative changes in the MAF or the predominant flora in our patients with UC, regardless of disease activity or treatment.

\section{Discussion}

Most investigations into the rôle of the intestinal flora in the aetiology and pathogenesis of UC have concentrated on the faecal flora. ${ }^{5,6,28-34}$ The study of the pathogenic or protective effects of the MAF of the colorectum might be of greater relevance due to its unique anatomical position. However, the composition and control of this flora are poorly understood.

We chose to study the MAF of rectal biopsy tissue taken at routine sigmoidoscopy because no bowel preparation whatsoever is required for this procedure. Alternative sources of tissue would be colonoscopic biopsy samples or resected tissue taken during abdominal surgery. The use of purgatives, laxatives, antimicrobial agents and enemas before such procedures would be expected to affect the flora, although one study $^{35}$ found the MAF to be less altered by such procedures than the luminal flora.

The method adopted for washing the tissue sample free of loosely adherent mucus and faecal material is 
Table VI. The predominant flora of the MAF: the percentage of samples in each patient group in which a given major bacterial group predominated

\begin{tabular}{|c|c|c|c|c|c|c|c|}
\hline \multirow{3}{*}{$\begin{array}{l}\text { Predominant } \S \\
\text { bacterial } \\
\text { group }\end{array}$} & \multicolumn{7}{|c|}{ Percentage of samples from } \\
\hline & \multicolumn{3}{|c|}{$\begin{array}{c}\text { new UC at } \\
\text { (weeks) }\end{array}$} & \multirow{2}{*}{$\begin{array}{c}\text { quiescent } \\
\text { UC } \\
(n=44)\end{array}$} & \multicolumn{3}{|c|}{$\begin{array}{l}\text { relapsed UC at } \\
\text { (weeks) }\end{array}$} \\
\hline & $\begin{array}{c}0 \\
(n=25)\end{array}$ & $\begin{array}{c}3 \\
(n=25)\end{array}$ & $\begin{array}{c}12 \\
(n=24)\end{array}$ & & $\begin{array}{c}0 \\
(n=20)\end{array}$ & $\begin{array}{c}3 \\
(n=17)\end{array}$ & $\begin{array}{c}12 \\
(n=16)\end{array}$ \\
\hline Anaerobic cocci & $40 \%$ & $29 \%$ & $17 \%$ & $23 \%$ & $35 \%$ & $24 \%$ & $47 \%$ \\
\hline Bacteroides & $36 \%$ & $17 \%$ & $38 \%$ & $20 \%$ & $40 \%$ & $41 \%$ & $38 \%$ \\
\hline Bifidobacteria & $0 \%$ & $8 \%$ & $17 \% *$ & $39 \% \dagger$ & $20 \% \dagger$ & $12 \%$ & $13 \%$ \\
\hline Streptococci & $16 \%$ & $21 \%$ & $0 \%^{*}$ & $5 \%$ & $10 \%$ & $12 \%$ & $0 \%$ \\
\hline Other genera & $12 \%$ & $33 \%$ & $42 \% *$ & $18 \%$ & $20 \%$ & $24 \%$ & $13 \%$ \\
\hline
\end{tabular}

* Significantly different $(\mathrm{p}<0.05)$ from patients with "new" untreated UC.

+ Significantly different $(\mathrm{p}<0.001)$ from patients with "new" untreated UC.

$\S$ In some samples there was no single predominant bacterial group, hence the values for each patient group do not total $100 \%$

clearly an important consideration in determining the nature of the flora. We found logarithmic counts of $<3 \cdot 0-8 \cdot 3 / \mathrm{g}$ wet weight in samples from the rectosigmoid. Although gentler washing techniques have been used in other studies ${ }^{7,8}$ this did not result in large differences in counts. Logarithmic counts of 5.5-9.9/g were reported from unwashed colonoscopic biopsy specimens, ${ }^{9}$ depending on the biopsy site, with $6.7-$ $8.4 / \mathrm{g}$ in samples from the sigmoid colon. Lightlywashed tissue samples removed surgically from four sudden-death patients ${ }^{8}$ yielded $6 \cdot 2-8 \cdot 4 / \mathrm{g}$ depending on site, with $6 \cdot 5-8 \cdot 4 / \mathrm{g}$ in samples from the sigmoid colon. In agreement with these and other studies, ${ }^{11,35}$ we found considerable variation in the colorectal MAF between individuals; similar variation is found in the faecal microflora. ${ }^{36,37}$ Direct comparisons between studies are problematic because of differences in patients, treatments, types of samples, anaerobic technique and media used.

Our results indicate that the bacterial flora of the colorectal mucosal surface is not appreciably altered by bowel dysfunction such as bleeding and diarrhoea in contrast to the faecal flora of patients with inflammatory bowel disease. ${ }^{11,33,34,38}$ This adds support to the hypothesis that alterations to the MAF in patients with UC might be of greater significance to the pathogenesis of this disease than changes in the faecal flora.

It is interesting to note that we saw neither overgrowth by, nor loss of, any individual component of the flora in active disease or during treatment, although in active disease the numbers and complexity of the flora were reduced and the predominant genera were altered. With the exception of $C$. difficile found in three patients during treatment, enteric pathogens were not isolated. Patients with inflammatory bowel disease (IBD) given antimicrobial treatment, including sulphasalazine, suffer from loss of colonisation resistance as evidenced by detection of $C$. difficile or its toxin. ${ }^{39-41}$ However, the consensus view appears to be that this is no different from comparable nonIBD patients exposed to similar treatments; in patients with IBD the infection is normally self-limiting and of doubtful pathological significance. Our three patients followed an unremarkable clinical course and appeared unaffected by mucosal colonisation with $C$. difficile. Spirochaetes or campylobacters were neither observed nor cultured from our patients, in contrast to the characteristic spirochaetal overgrowth of the rectal MAF in the proctitis associated with gay-bowel syndrome. ${ }^{20}$ We did not observe the unusual large spiral or helical bacteria described by Croucher et al. ${ }^{8}$ however, we did not examine the biopsy specimens microscopically before the maceration step which might have physically disrupted these bacteria.

Although it was evident that individual patients tended to carry phenotypically similar isolates through sequential samples, we found specific and significant changes in the MAF of patients suffering their first attack of colitis compared to the flora in quiescent UC. The effect of treatment was particularly interesting: the proportion of samples in which anaerobic gram-positive cocci and facultative streptococci were the predominant flora decreased during treatment, whereas the proportion with bifidobacteria predominant increased and approached the frequency found in the quiescent disease group. It is possible that speciation may reveal more subtle changes within this flora with respect to disease activity. The MAF of relapsed UC patients was also altered but not to the same degree as that seen in patients at first presentation; this is not inconsistent with chronic inflammatory bowel disease causing a persistent alteration in this flora.

Enterobacteria, predominantly Escherichia coli, have been linked to colitis in various studies. ${ }^{28,42-45}$ They were isolated infrequently from the MAF in our patients and always in low numbers. There were significantly fewer $E$. coli in untreated patients with active disease. This study shows that other bacterial groups, such as the bacteroides and aerobic and anaerobic gram-positive cocci were isolated far more commonly from patients with active colitis, whether at first onset or upon relapse; these may be more relevant candidates for future studies into the rôle of micro-organisms in UC. 
We are grateful to the National Association for Colitis and Crohn's Disease (NACC), the British Digestive Foundation (Wolverhampton Appeal) and the Public Health Laboratory Service Board for financial support. We thank Drs Sue Scotton and Carol Walters (Royal Hospital, Wolverhampton) for their valuable clinical

\section{References}

1. Kirsner JB, Shorter RG. Recent developments in "nonspecific" inflammatory bowel disease. $N$ Engl J Med 1982; 306: 775 785

2. Jewell DP, Rhodes JM. Immunology of ulcerative colitis. In: Allan RN, Keighley MRB, Alexander-Williams J, Hawkins C (ed) Inflammatory bowel diseases. Edinburgh, Churchill Livingstone. 1983: 154-170.

3. Zinberg, J. Vecchi M, Sakamaki S et al. Intestinal tissue associated antigens in the pathogenesis of inflammatory bowel disease. In: Järnerot $G$ (ed) Inflammatory bowel disease. New York, Raven Press. 1987: 67-81.

4. Halstensen TS, Mollnes TE, Garred P, Fausa O, Brandtzaeg P. Epithelial deposition of immunoglobulin $G_{1}$ and activated complement $\left(\mathrm{C} 3_{\mathrm{b}}\right.$ and terminal complement complex $)$ in ulcerative colitis. Gastroenterology 1990; 98: 1264-1271.

5. Kirsner JB, Shorter RG. Recent developments in nonspecific inflammatory bowel disease. $N$ Engl J Med 1982; 306: 837 848

6. Thayer WR. Infectious agents in inflammatory bowel disease. In: Järnerot $G$ (ed) Inflammatory bowel disease. New York, Raven Press. 1987: 101-107.

7. Hartley CL, Neumann CS, Richmond MH. Adhesion of commensal bacteria to the large intestine wall in humans. Infect Immun 1979; 23: 128-132.

8. Croucher, SC, Houston AP, Bayliss CE, Turner RJ. Bacterial populations associated with different regions of the human colon wall. Appl Environ Microbiol 1983; 45: 1025-1033.

9. Edmiston CE, Avant GR, Wilson FA. Anaerobic bacterial populations on normal and diseased human biopsy tissue obtained at colonoscopy. Appl Environ Microbiol 1982; 43: 1173-1181.

10. Peach S, Lock MR, Katz D, Todd IP, Tabaqchali S. Mucosalassociated bacterial flora of the intestine in patients with Crohn's disease and in a control group. Gut 1978; 19 : 10341042.

11. Hudson MJ, Hill MJ, Elliott PR, Berghouse LM, Burnham WR, Lennard Jones JE. The microbial flora of the rectal mucosa and faeces of patients with Crohn's disease before and during antimicrobial chemotherapy. $J$ Med Microbiol 1984; 18: 335-345.

12. Crowther JS. Transport and storage of faeces for bacteriological examination. J Appl Bacteriol 1971; 34: 477-483.

13. Berghouse L, Hori S, Hill M, Hudson M, Lennard-Jones JE, Rogers E. Comparison between the bacterial and oligosaccharide content of ileostomy effluent in subjects taking diets rich in refined or unrefined carbohydrate. Gut 1984; 25: $1071-1077$.

14. Borriello $\mathbf{P}$, Hudson $\mathbf{M}$, Hill M. Investigation of the gastrointestinal bacterial flora. Clin Gastroenterol 1978 7: 329-349.

15. Eller C, Crabill MR, Bryant MP. Anaerobic roll tube media for nonselective enumeration and isolation of bacteria in human feces. Appl Microbiol 1971 ; 22 : 522-529.

16. Koopman JP, Kennis HM. The influence of media on the recovery of bacteria from the normal mouse caecum. $L a b$ Anim 1982; 16: 364-368.

17. Miles AA, Misra SS, Irwin JO. The estimation of the bactericidal power of the blood. J Hyg 1938; 38: 732-749.

18. Barr GD, Hudson MJ, Priddle JD, Jewell DP. Colonic bacterial proteases to $\operatorname{Ig} A_{1}$ and $\operatorname{sgA}$ in patients with ulcerative colitis. Gut 1987; 28: 186-189.

19. Sutter VL, Citron DM, Finegold SM. Wadsworth anaerobic bacteriology manual, 3rd ed. St Louis, CV Mosby Co. 1980: 99.

20. Cooper C, Cotton DWK, Hudson MJ, Kirkham N, Wilmott FEW. Rectal spirochaetosis in homosexual men: characterisation of the organism and pathophysiology. Genitourin Med 1986; 62: 47-52.

21. Koransky JR, Allen SD, Dowell VR. Use of ethanol for selective isolation of sporeforming microorganisms. Appl Environ Microbiol 1978; 35: 762-765.

22. Caldwell DR, Bryant MP. Medium without rumen fluid for nonselective enumeration and isolation of rumen bacteria. Appl Microbiol 1966; 14 : 794-801. assistance and Mrs Cherry Sell and Mrs Veronica Brown (Royal Hospital, Wolverhampton) for collation of patient data. Our thanks also to Dr C. P. Farrington (PHLS Communicable Disease Surveillance Centre) for statistical advice.

23. Mitsuoka T. A color atlas of anaerobic bacteria. Tokyo, Soubunsha. 1980: 323-324.

24. Holdeman LV, Cato EP, Moore WEC (eds) Anaerobe laboratory manual, 4th edn. Blacksburg, VA, Virginia Polytechnic Institute and State University. 1977: 146.

25. Hungate RE, Stack RJ. Phenylpropanoic acid: growth factor for Ruminococcus albus. Appl Environ Microbiol 1982; 44: 79-83.

26. Balch WE, Fox GE, Magrum LJ, Woese CR, Wolfe RS. Methanogens: reevaluation of a unique biological group. Microbiol Rev 1979; 43: 260-296.

27. Best WR. On the logarithmic transformation of intestinal bacterial counts. Amer J Clin Nutr 1970; 23: 1608-1609.

28. Cooke EM. A quantitative comparison of the faecal flora of patients with ulcerative colitis and that of normal persons. J Pathol Bacteriol 1967; 94: 439-444.

29. Gorbach SL, Nahas L, Plaut AG, Weinstein L, Patterson JF, Levitan R. Studies on intestinal microflora. V. Fecal microbial ecology in ulcerative colitis and regional enteritis: relationship to severity of disease and chemotherapy. Gastroenterology $1968 ; 54: 575-587$.

30. West B, Lendrum R, Hill MJ, Walker G. Effects of sulphasalazine (Salazopyrin) on faecal flora in patients with inflammatory bowel disease. Gut 1974; 15: 960-965.

31. van der Wiel-Korstanje JAA, Winkler KC. The faecal fora in ulcerative colitis. J Med Microbiol 1975; 8: 491-501.

32. Keighley MRB, Arabi Y, Dimock F, Burdon DW, Allan RN Alexander-Williams J. Influence of inflammatory bowel disease on intestinal flora. Gut 1978; 19 : 1099-1104.

33. Hori S, Shimoyama T. Bacterial groups of the intestinal microflora in inflammatory bowel disease in Japan. In: Shiratori T, Nakano H (eds) Inflammatory bowel disease. (Japan Medical Research Foundation publication no. 22.) Tokyo, University of Tokyo Press. 1982: 23-33.

34. Mitsuoka T, Benno Y. Bacterial species of the intestinal flora of patients with inflammatory bowel disease. In: Shiratori T, Nakano H (eds) Inflammatory bowel disease. (Japan Medical Research Foundation publication no. 22.) Tokyo, University of Tokyo press. 1982: 35-42.

35. Marks CG, Hawley PR, Peach SL, Drasar BS, Hill MJ. The effects of phthalylsulphathiazole on the bacteria of the colonic mucosa and intestinal content as revealed by the examination of surgical samples. Scand J Gastroenterol $1979 ; 14: 891-896$.

36. Finegold, SM, Flora DJ, Attebery HR, Sutter VL. Fecal bacteriology of colonic polyp patients and control patients Cancer Res 1975; 35: 3407-3417.

37. Holdeman LV, Good IJ, Moore WEC. Human fecal flora variation in bacterial composition within individuals and a possible effect of emotional stress. Appl Environ Microbiol $1976 ; 31$ : 359-375.

38. Wensinck F, Custers-van Lieshout LMC, Poppelaars-Kustermans PAJ, Schröder AM. The faecal flora of patients with Crohn's disease. J Hyg 1981; 87: 1-12.

39. Meyers S, Mayer L, Bottone E, Desmond E, Janowitz, HD. Occurrence of Clostridium difficile toxin during the course of inflammatory bowel disease. Gastroenterology $1981 ; \mathbf{8 0}$; 697-700.

40. Keighley MRB, Youngs D, Johnson M, Allan RN, Burdon DW. Clostridium difficile toxin in acute diarrhoea complicating inflammatory bowel disease. Gut $1982 ; 23: 410-414$

41. Greenfield C, Aguilar Ramirez JR, Pounder RE et al. Clostridium difficile and inflammatory bowel disease. Gut 1983; 24: 713-717.

42. Cooke EM, Ewins SP, Hywel-Jones J, Lennard-Jones JE. Properties of strains of Escherichia coli carried in different phases of ulcerative colitis. Gut 1974; 15: 143-146.

43. Burke DA, Axon ATR. Adhesive Escherichia coli in inflammatory bowel disease and infective diarrhoea. $B r$ Med $J 1988$; 297: $102-104$

44. Burke DA, Axon ATR. Ulcerative colitis and Escherichia coli with adhesive properties. J Clin Pathol 1987; 40: 782-786.

45. Burke DA, Axon ATR. Hydrophobic adhesion of Escherichia coli in ulcerative colitis. Gut $1988 ; 29: 41-43$. 